\title{
Shenqi Fuzheng Injection (SFI) Enhances IFN- $\alpha$ Inhibitory Effect on Hepatocellular Carcinoma Cells by Reducing VEGF Expression: Validation by Gene Silencing Technique
}

\author{
Xiaoheng Chen $\mathbb{D}^{1},{ }^{1}$ Shuo Qi $\mathbb{D},{ }^{1}$ Zhe Li, ${ }^{1}$ Bei He, ${ }^{2}$ Hui long Li, ${ }^{1}$ \\ Jinxiang Fu, ${ }^{1}$ Sheng Huang, ${ }^{1}$ Lei Zhang, ${ }^{1}$ Xinai Li, ${ }^{1}$ Rui Hu, ${ }^{1}$ Lu Li, ${ }^{1}$ \\ Tangshun Wang, ${ }^{1}$ Feng Xue, ${ }^{1}$ Xiang Gao, ${ }^{1}$ Xiaoguang Shi, ${ }^{1}$ Tao Zhang, ${ }^{1}$ Xin Wang, \\ Junhui Wang, ${ }^{3}$ and Zhiguo Ding $\mathbb{D}^{1}$ \\ ${ }^{1}$ Department of Surgery, Dongzhimen Hospital of Beijing University of Chinese Medicine, Beijing, China \\ ${ }^{2}$ Department of Medical Service, The Third Clinical Medical College of Beijing University of Chinese Medicine, Beijing, China \\ ${ }^{3}$ Department of Physiology, Faculty of Medicine, University of Toronto, Toronto, Canada
}

Correspondence should be addressed to Zhiguo Ding; dingzhiguo_1@163.com

Received 12 November 2018; Revised 22 March 2019; Accepted 28 March 2019; Published 23 April 2019

Academic Editor: Guangcun Huang

Copyright (C) 2019 Xiaoheng Chen et al. This is an open access article distributed under the Creative Commons Attribution License, which permits unrestricted use, distribution, and reproduction in any medium, provided the original work is properly cited.

\begin{abstract}
Shenqi Fuzheng Injection (SFI) is a traditional Chinese medicine injection with anticancer properties and is mainly composed of ginseng and astragalus. Its efficacy has been confirmed in clinical trials, but the mechanism remains unclear. We investigated the effect of SFI on vascular endothelial growth factor (VEGF) gene expression in hepatocellular carcinoma (HCC) cells and identified its possible mechanism of synergistic effects when combined with the chemotherapeutic drug interferon (IFN-) $\alpha$. An MTT assay was used to measure the inhibition effects of low-dose IFN- $\alpha$ (6000 IU) with or without SFI $(0.5 \mathrm{~g} / \mathrm{L})$ on the HCC cell line MHCC97. VEGF-silenced MHCC97L-mir200 cell lines were prepared using lentiviral vectors and evaluated by real-time PCR to determine the inhibition effect. We examined MHCC97L-mir200 and MHCC97L cells by MTT assay, using IFN- $\alpha$ alone or in combination with SFI. The inhibition ratio of IFN- $\alpha(6000 \mathrm{IU})$ was $-29.5 \%$, while that for IFN- $\alpha(6000 \mathrm{IU})+\mathrm{SFI}(0.5 \mathrm{~g} / \mathrm{L})$ was $17.0 \%$, which was significantly higher than that for the IFN- $\alpha$ group $(\mathrm{P}<0.01)$. The VEGF gene was silenced successfully in MHCC97-L cells. After interference of VEGF, the inhibition by SFI and IFN- $\alpha$ in MHCC97L-mir200 did not differ from that in MHCC97-L cells (P > 0.05). SFI can reduce the expression of VEGF in HCC, which can increase the efficacy of IFN- $\alpha$, providing a theoretical basis for clinical application.
\end{abstract}

\section{Introduction}

Hepatocellular carcinoma (HCC) is a primary liver tumor and the most difficult human malignancy to treat. [1]. High rates of recurrence and metastasis after operation have become a bottleneck for improving the long-term efficacy, which is a key point in overcoming HCC. Interferon (IFN-) $\alpha$ is a chemotherapeutic drug that is widely used in the clinical treatment of HCC [2] and has various effects, such as resistance to viral infections, immune function, inhibition of cell proliferation, and apoptosis induction [3-6].
Angiogenesis is essential in the process of carcinogenesis to facilitate tumor progression and metastasis. Vascular endothelial growth factor (VEGF) is a well-characterized angiogenic factor known to stimulate angiogenesis within a tumor [7]. Studies have shown that increased expression of VEGF is an important factor in the recurrence and metastasis of HCC [8].

Previous studies showed that SFI can improve the survival time of HCC patients after operation, while also improving their quality of life [9-11].

The main components of Shenqi Fuzheng injection are ginseng and astragalus root. Ginseng has been traditionally 
used as a medicinal herb and food ingredient in dishes since ancient times in Asia and is now popular worldwide. Ginseng contains various bioactive components, including ginsenosides, phenolic compounds, polysaccharides, alkaloids, polyacetylenes, peptides, and fatty acids. The pharmacological effects of ginseng have been demonstrated in the nervous centralis, cardiovascular, and immune systems [12]. In addition, ginseng has been proposed to have chemopreventive effects on cancers of the lung and colon in animals and humans [13]. Among the constituents of ginseng, ginsenosides and polyacetylenes (the main components of ginseng) have been shown to decrease the malignant potential of liver cancer [14]. The dried root of Astragalus membranaceus (Radix Astragali) has a long history of medicinal use in traditional Chinese medicine for treating the common cold, diarrhea, fatigue, and anorexia as an immunomodulating agent in mixed herbal decoctions [15]. In contemporary pharmacotherapy, R. astragali has been used to ameliorate the side-effects of cytotoxic antineoplastic drugs [16]. Among its different constituents, Astragalus polysaccharides have been widely studied, particularly for their immunopotentiating properties, such as the stimulation of B cell proliferation and cytokine production in murine [17]. Additionally, clinical studies have shown that Astragalus polysaccharides can counteract the side-effects of chemotherapeutic drugs, including significantly attenuating myelosuppression in cancer patients [18].

In a previous study, we found that SFI can decrease various cytokines to reduce the invasiveness of cancer and enhance anticancer effects [19]. Therefore, this study of SFI focused on the expression of VEGF in the human HCC cell line MHCC97-L and its effects on VEGF expression of HCC cells.

\section{Materials and Methods}

2.1. Cell Culture. MHCC97-L cell lines were placed in $10 \%$ DMEM medium containing 10\% fetal bovine serum (FBS) and penicillin $(100 \mathrm{U} / \mathrm{mL})$ and streptomycin $(100 \mu \mathrm{g} / \mathrm{mL})$. Cell culture was performed at $37^{\circ} \mathrm{C}$ in humidified atmosphere containing $5 \% \mathrm{CO}_{2}$. The cells were detached every 2-3 days with $0.25 \%$ trypsin/EDTA. The medium was exchanged after each passage. Cells were cultured for $24 \mathrm{~h}$ before initiation of the experiments.

2.2. Materials. Shenqi Fuzheng Injection (Li Beads group Limin Pharmaceutical, Shaoguan, China, S20110107), restructuring human interferon alpha-1B injection (Tri-prime gene limited, Beijing, China, S20010007), BCA protein concentration determination reagents box, predye protein markers, film closed liquid and ELC glow liquid (Thermo Fisher Scientific, Waltham, MA, USA); rat anti-people ICAM-1 monoclonal antibodies and rat anti-people STAT1 monoclonal antibodies (BD Biosciences, Franklin Lakes, NJ, USA); rabbit anti-people p-STAT1 monoclonal antibodies (Cell Signaling Technology, Danvers, MA, USA); anti-proliferating cell nuclear antigen monoclonal antibodies in rats (Abcam, Cambridge, UK), MTT, rat anti- $\beta$--actin monoclonal antibodies, horseradish peroxidase-conjugated goat anti-rat Mark II antirabbit and goat II antibodies (Santa Cruz Biotechnology,
Dallas, TX, USA), Platinum HIFI Taq Polymerase, Trizol Reagent, $5 \times$ First-Strand buffer, 0.1 M DTT, SYBR Green I, Rnase out, oligo dT/Random primer, $10 \times \mathrm{PCR}$ Buffer, $\mathrm{Mg}^{2+}(50 \mathrm{mM})$, Platinum Taq DNA Polymerase, $100 \mathrm{mM}$ DNTPs (Invitrogen, Carlsbad, CA, USA), t-carrier, plenti6.3 MIR load, 293 cells, DH5 Alpha cells, ddwater (Heino bio Technology Ltd.), T4 Ligase (New England Biolabs, Ipswich, MA, USA); DMEM Medium, Hyclone, Logan, UT, USA); FBS (Biowest Company); 24 holes and 6-well cell culture plates (Corning), fluorescent Optical microscope (Olympus Corporation), fluorescence quantitative PCR instrument (Bio Rad).

\subsection{Methods}

2.3.1. Cell Viability Assay of MHCC97L. To investigate whether the growth of the MHCC97L cell lines was inhibited and the extent of inhibition under SFI and IFN- $\alpha$, a cell viability assay (MTT) was performed. Briefly, MHCC97L cells were seeded at a density of 40,000 cells/well in $0.2 \mathrm{~mL}$ in 96-well plates in the culture medium described above. After $24 \mathrm{~h}$, SFI $(0.5 \mathrm{~g} / \mathrm{L}) 20 \mu \mathrm{L}$, IFN- $\alpha(6000 \mathrm{IU}) 20 \mu \mathrm{L}$, or SFI $(0.5 \mathrm{~g} / \mathrm{L}) 10 \mu \mathrm{L}+\mathrm{IFN}-\alpha$ (6000 IU) were added separately to the wells. Cells treated with phosphate-buffered saline were used as a negative control. After $72 \mathrm{~h}$ incubation (5\% $\left.\mathrm{CO}_{2}, 37^{\circ} \mathrm{C}\right), 15 \mu \mathrm{L}$ MTT solution was added to each well to reach a final concentration of $10 \mathrm{mg} / \mathrm{mL}$. After further incubation for $2 \mathrm{~h}\left(5 \% \mathrm{CO}_{2}, 37^{\circ} \mathrm{C}\right)$, the cells were shaken for $5 \mathrm{~min}$ in a microvibration shaker at $4^{\circ} \mathrm{C}$ and the medium was removed. Formazan crystals present in the mitochondria of metabolically active cells were solubilized with $100 \mu \mathrm{L}$ of dimethyl sulfoxide, and the dye concentration was measured using an EL $\times 800$ Microplate Reader (BioTek, Norcross, GA, USA) at a wavelength of $570 \mathrm{~nm}$.

2.3.2. Construction and Identification of Lentiviral Vector. MRNA interference sequences (Table 1) of the human VEGF gene (NCBI GenBank Gene ID: AF022375) were designed by using "BLOCK IT RNAi DESIGNER" (Invitrogen). Each complementary single strand $(5 \mu \mathrm{L})$ was mixed for annealing. The 4 oligo mixtures were heated at $95^{\circ} \mathrm{C}$ for $5 \mathrm{~min}$, and then cooled for $20 \mathrm{~min}$ to form a double-chain oligo, which was connected to the linearized plenti6.3-MIR carrier to construct 2 miRNA lentiviral vector plasmids. The lentiviral vector was transformed into $\mathrm{DH} 5 \alpha$ cells. Positive clones were screened by colony PCR with vector universal primers.

2.3.3. Package of Lentivirus. Growing the $293 \mathrm{~T}$ cells in log phase. After counting the cells, each Petri dish was inoculated with $6 \times 10^{6}$ cells and incubated overnight at $37^{\circ} \mathrm{C}$ and $5 \%$ $\mathrm{CO}_{2}$. The culture medium was removed before transfection and $5 \mathrm{~mL}$ Opti-MEM medium was added. Next, $9 \mu \mathrm{g}$ packaging mixture and $3 \mu \mathrm{g} 1.5 \mathrm{~mL}$ lentiviral expression plasmid were added to Opti-MEM $\left(37^{\circ} \mathrm{C}\right.$ preheated $)$ and mixed gently. After adding $36 \mu \mathrm{L}$ Lipofectamine 2000 to $1.5 \mathrm{~mL}$ Opti-MEM, the samples were mixed gently and placed for $5 \mathrm{~min}$ at $28^{\circ} \mathrm{C}$. The plasmid solution and Lipofectamine 2000 were mixed gently and incubated for $20 \mathrm{~min}$ at room temperature. Plasmid-liposome compound $(3 \mathrm{~mL})$ was carefully added to cells in the Petri dish, mixed gently, and incubated for $6 \mathrm{~h}$ at 
TABLE 1: miRNA oligo sequences (with negative control).

\begin{tabular}{lc}
\hline oligo & Oligo sequences $5^{\prime}$ to $3^{\prime}$ \\
\hline $200-\mathrm{F}$ & TGCTGTGAAGATGTACTCGATCTCATGTTTTGGCCACTGACTGACATGAGATCGTACATCTTCA \\
\hline $200-\mathrm{R}$ & CCTGTGAAGATGTACGATCTCATGTCAGTCAGTGGCCAAAACATGAGATCGAGTACATCTTCAC \\
\hline Negative-F & TGCTGAAATGTACTGCGCGTGGAGACGTTTTGGCCACTGACTGACGTCTCCACGCAGTACATTT \\
\hline Negative-R & CCTGAAATGTACTGCGTGGAGACGTCAGTCAGTGGCCAAAACGTCTCCACGCGCAGTACATTTC \\
\hline
\end{tabular}

$37^{\circ} \mathrm{C}$ and $5 \% \mathrm{CO}_{2}$, after which the culture was replaced with DMEM containing $10 \%$ FBS. The supernatant was collected after $48 \mathrm{~h}$ cell culture and centrifuged for $10 \mathrm{~min}$ at 1509.3 $\mathrm{xg}(3000 \mathrm{rmp})$. Cells and debris were removed using a $0.45-$ $\mu \mathrm{m}$ filter. The stock solution of virus was separated in an ultracentrifuge at $50,000 \times g$ for $2 \mathrm{~h}$, the supernatant was removed, and the pellet was resuspended in $200 \mu \mathrm{L}$ DMEM and stored at $-80^{\circ} \mathrm{C}$.

2.3.4. Determination of Lentivirus. 293T cells were allowed to stand for one day before the measurements. Approximately 8000 cells in $100 \mu \mathrm{L}$ were added to each well. The stock solution of virus was diluted to different concentrations (each $50-\mu \mathrm{L}$ sample contained $1 \times 10^{-3}$ to $1 \times 10^{-8} \mathrm{~mL}$ of lentivirus), and the original medium was removed from the 96-well plates. The lentiviral dilution medium was added at $50 \mu \mathrm{L}$ per well and mixed gently. Each dilution was tested in triplicate. After incubation for $48 \mathrm{~h}$ at $37^{\circ} \mathrm{C}$ and $5 \% \mathrm{CO}_{2}$, we added $100 \mu \mathrm{L}$ of new medium to each well. Five days later, fluorescence signals were observed.

2.3.5. Infection of MHCC97L and Real-Time PCR Detection of VEGF Expression. MHCC97L cells were cultured to the log phase and then infected for $6 \mathrm{~h}$ at a multiplicity of infection of 100. The culture medium was replaced with complete medium (without blasticidin) for the negative group and control group. After the cells were cultivated for $48 \mathrm{~h}, 5 \mu \mathrm{g} / \mathrm{mL}$ blasticidin was added every $2-3$ weeks (replaced fresh culture medium with antibiotics every 3-4 days). Cell death and the fluorescence ratio were observed by fluorescence microscopy. Cells were cultured until the cell fluorescence ratio reached above $90 \%$.

After infecting MHCC97L cells for $48 \mathrm{~h}$, we extracted cell RNA according to the Trizol cleavage fluid instructions and conducted RT-PCR reaction following the reverse transcription kit instructions. The primer sequences were as follows: VEGF upstream primer $5^{\prime}$-ACTGCCATCCAATCGAGACCC- $3^{\prime}$, downstream primer $5^{\prime}$-TGAGGTTTGATCCGCATAATC- $3^{\prime}, \beta$-Actin upstream primer $5^{\prime}$ ACTCTTCCAGCCTTCCTTCC-3', downstream primer $5^{\prime}$ GTACTTGCGCTCAGGAGGAG-3' ${ }^{\prime}$. The reaction system was formulated according to real-time PCR kit and amplified under the following conditions: predenaturation at $95^{\circ} \mathrm{C}$ for $120 \mathrm{~s}, 95^{\circ} \mathrm{C}$ for $10 \mathrm{~s}, 60^{\circ} \mathrm{C}$ for $30 \mathrm{~s}$, and $70^{\circ} \mathrm{C}$ for $45 \mathrm{~s}$ for 40 cycles, and the real-time fluorescence signal was detected. MHCC97-blank group cells were used as a control, and the relative quantification was calculated by using the $2^{-\triangle \triangle C T}$ (CT means cycle threshold) method.
2.3.6. Cell Viability Assay of MHCC97L-mir200. The cell viability assay (MTT) was performed again with VEGF gene silencing in MHCC97L cells (MHCC97L-mir200) to investigate the difference in the inhibition rate from normal MHCC97L cells. MHCC97L cells were seeded into 96-well plates at a density of 40,000 cells/well in $0.2 \mathrm{~mL}$ of the above-specified culture medium. After $24 \mathrm{~h}$, SFI $(0.5 \mathrm{~g} / \mathrm{L})$ $20 \mu \mathrm{L}$, IFN- $\alpha$ (6000 IU) $20 \mu \mathrm{L}$, or SFI $(0.5 \mathrm{~g} / \mathrm{L}) 10 \mu \mathrm{L}+\mathrm{IFN}-\alpha$ (6000 IU) were separately added to the wells. As a negative control, some cells were treated with phosphate-buffered saline. After $72 \mathrm{~h}$ incubation $\left(5 \% \mathrm{CO}_{2}, 37^{\circ} \mathrm{C}\right), 15 \mu \mathrm{L}$ MTT solution was added to each well to reach a final concentration of $10 \mathrm{mg} / \mathrm{mL}$. After further incubation for $2 \mathrm{~h}\left(5 \% \mathrm{CO}_{2}\right.$, $37^{\circ} \mathrm{C}$ ) the cells were shaken for $5 \mathrm{~min}$ on a microvibration Shaker at $4^{\circ} \mathrm{C}$ and the medium was removed. Formazan crystals present in the mitochondria of metabolically active cells were solubilized with $100 \mu \mathrm{L}$ of dimethyl sulfoxide, and the dye concentration was measured by using an EL $\times 800$ Microplate Reader at a wavelength of $570 \mathrm{~nm}$.

\section{Results}

3.1. SFI Increases the Inhibitory Effect of IFN- $\alpha$ on $M H C C 97 L$ Cells. In the analysis of the inhibition ratio of $M H C C 97 \mathrm{~L}$ cells with a low dose of IFN- $\alpha$ (6000 IU), SFI $(0.5 \mathrm{~g} / \mathrm{L})$, and IFN- $\alpha(6000 \mathrm{IU})+$ SFI $(0.5 \mathrm{~g} / \mathrm{L})$, the results showed that the inhibition ratio of a low dose of IFN- $\alpha$ (6000 IU) was $29.5 \%$, while the value for SFI $(0.5 \mathrm{~g} / \mathrm{L})$ was $-27.4 \%$, and IFN- $\alpha$ $(6000 \mathrm{IU})+$ SFI $(0.5 \mathrm{~g} / \mathrm{L})$ was $17.0 \%$, which was significantly higher than that for the IFN- $\alpha$ (6000 IU) and the SFI $(0.5 \mathrm{~g} / \mathrm{L})$ group ( $\mathrm{P}<0.01$, compared to IFN- $\alpha$ and the SFI control group) (Figure 1).

3.2. SFI Decreases the Expression of VEGF on MHCC97L Cells. Western blot was used to analyze the VEGF expression of MHCC97L cells with a low dose of IFN- $\alpha$ (6000 IU), SFI $(0.5 \mathrm{~g} / \mathrm{L})$, and IFN- $\alpha(6000 \mathrm{IU})+\mathrm{SFI}(0.5 \mathrm{~g} / \mathrm{L})$. The results showed that the VEGF protein expression of a low dose of IFN- $\alpha(6000 \mathrm{IU})$ was higher than that for SFI $(0.5 \mathrm{~g} / \mathrm{L})$ and IFN- $\alpha(6000 \mathrm{IU})+\mathrm{SFI}(0.5 \mathrm{~g} / \mathrm{L})$ group (Figure 2$)$.

3.3. Sequencing of Oligo Connected to plenti6.3-MIR. We determined the miRNA oligo sequences by sequencing to confirm that the oligo had been correctly connected to plenti6.3-MIR. The sequence was consistent with the expected result (Figure 3).

3.4. Lentiviral Packaging and Infection Succeeded. Twentyfour hours after the plenti6.3-MIG-200 transfection 


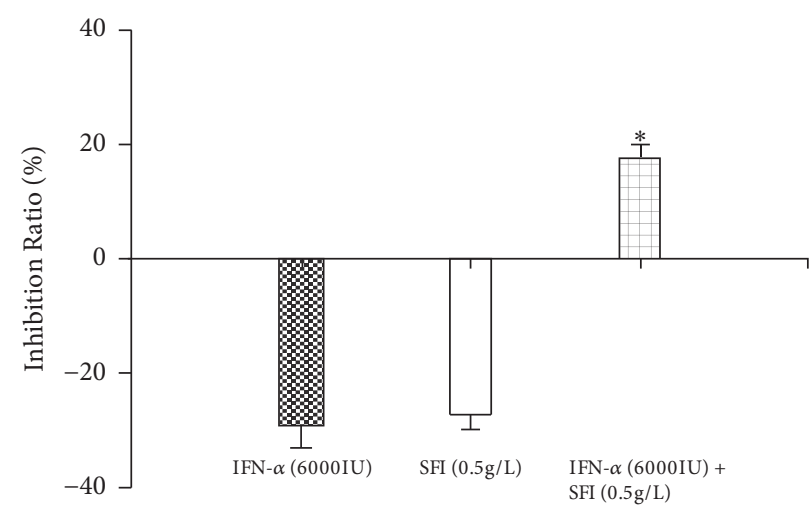

FIGURE 1: Inhibition ratio of SFI and INF- $\alpha$ on MHCC97L cells. $* \mathrm{P}<0.01$, compared with IFN- $\alpha$ and SFI control group, means \pm SEM, $\mathrm{n}=5$.

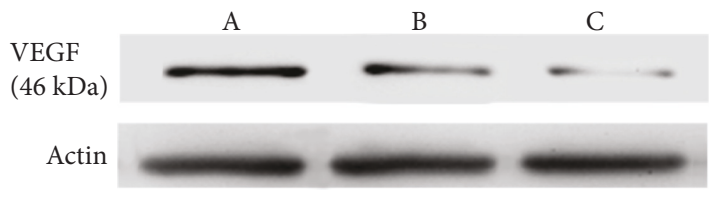

FIGURE 2: VEGF protein expression with SFI and INF- $\alpha$ treatment on MHCC97L cells. A. IFN- $\alpha$ (6000 IU); B. SFI ( $0.5 \mathrm{~g} / \mathrm{L})$; C. IFN- $\alpha$ $(6000 \mathrm{IU})+\mathrm{SFI}(0.5 \mathrm{~g} / \mathrm{L})$.

experiment, similar findings were noted under both fluorescence and visible light (Figures 4(a) and 4(b)). Most cells were found to emit fluorescence, and the RNAi lentiviral infection rate of MHCC97L cells was over $90 \%$ at $48 \mathrm{~h}$ (Figures 3(c) and 3(d)), indicating that the transfection was successful.

3.5. Real-Time PCR. Real-time PCR was conducted to detect VEGF expression, and PCR analysis showed that the interference efficiency of the VEGF gene was up to $72.2 \%$ in MHCC97L-mir200 (Table 2).

3.6. SFI Increases the Inhibitory Effect of IFN- $\alpha$ on MHCC97Lmir200 Cells. After the VEGF gene was silenced by siRNA, we analyzed the inhibition ratio again. The MHCC97Lmir200 cells were treated with a low dose of IFN- $\alpha$ (6000 IU), SFI $(0.5 \mathrm{~g} / \mathrm{L})$, and IFN $-\alpha(6000 \mathrm{IU})+\mathrm{SFI}(0.5 \mathrm{~g} / \mathrm{L})$. The results showed that the inhibition ratio of a low dose of IFN- $\alpha$ $(6000 \mathrm{IU})$ was $10.6 \%$, SFI $(0.5 \mathrm{~g} / \mathrm{L})$ was $11.5 \%$, while that of IFN- $\alpha(6000 \mathrm{IU})+$ SFI $(0.5 \mathrm{~g} / \mathrm{L})$ was $11.3 \%$. There was no significant difference between the IFN- $\alpha$ (6000 IU) group, the SFI group, and combined group ( $\mathrm{P}>0.05$, compared to the IFN- $\alpha$ and the SFI control group) (Figure 5).

\section{Discussion}

Many carcinomas have angiogenic mechanisms to induce tumor growth and disease progression [7]. VEGF signaling activates cellular pathways, which leads to the formation and branching of new tumor blood vessels, promotes rapid tumor growth, and facilitates metastatic potential [20]. Inhibiting the VEGF pathway may cause a rapid and sustained antitumor response [15]. SFI mainly contains A. membranaceus and ginseng. Formononetin is one of the constituents of $A$. membranaceus, and studies have shown that formononetin can downregulate the expression of VEGF [21]. Panax notoginseng saponins were extracted from ginseng and analyzed. They were suggested to downregulate vascular endothelial growth factors in atherosclerotic vessels [22]. Therefore, SFI may also reduce the expression of VEGF, playing a synergistic antitumor role with IFN- $\alpha$. First, the MTT assay results showed that SFI could indeed enhance the inhibitory effect of IFN $-\alpha$ in MHCC97L cells. To confirm that SFI has a key role in inhibiting the tumor by downregulating the expression of VEGF, we used siRNA to silence the VEGF gene in MHCC97L cells. To achieve this, we first constructed and packaged lentiviral vectors, which were used to infect MHCC97L cells and carried out real-time PCR detection of VEGF, which showed an interference efficiency of up to 72.2\%. After the MHCC97L-mir200 cell lines were prepared, another MTT assay was conducted. The results showed that after the VEGF gene was silenced, there was no difference in the inhibition rate between using IFN- $\alpha$ alone and in combination with SFI. This also indicates that SFI exerts its effects by regulating the expression of the VEGF gene. Our results further confirmed the beneficial effects of SFI on the VEGF expression in consistence with previous report [23]. Although SFI is widely in China as an adjuvant drug for many cancers, such as lung and gastric cancers, the underlying mechanism is barely known. Regulating immunity in cancer patients with chemotherapy is the popular theory about the compound [24], our study here expanded the understanding to another important signaling way by looking at the VEGF and angiogenesis. As shown here, the cotreatment of SFI and cytokines could synergistically boost the inhibitory effect of IFN- $\alpha$ on cancer cell lines. Our study may provide helpful information for the application of SFI with immunomodulators in the treatment of cancers.

\section{Conclusion}

In summary, SFI can downregulate VEGF expression in HCC cells in a synergistic manner with IFN- $\alpha$. VEGF is an 


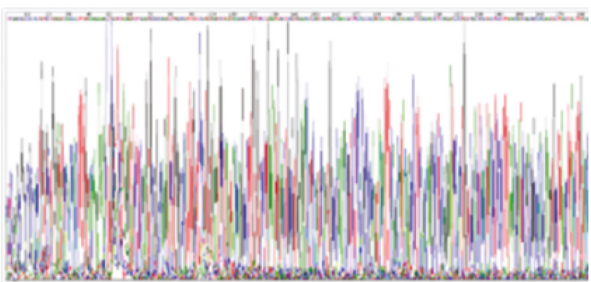

(a)

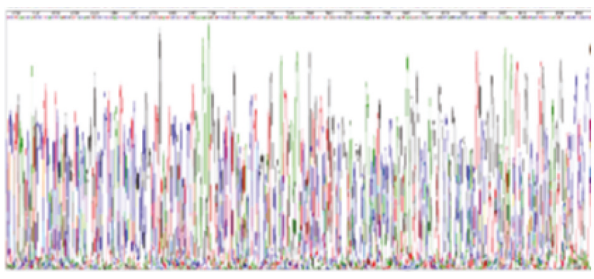

(c)

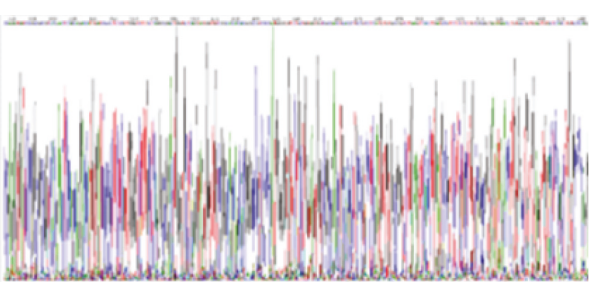

(b)

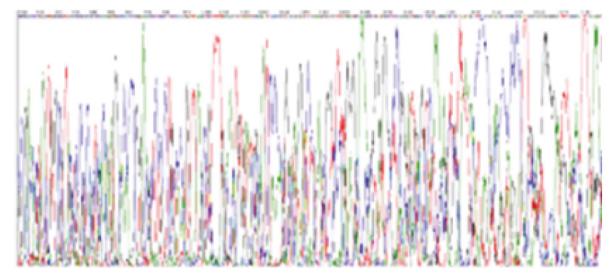

(d)

FIGURE 3: Sequencing results of oligo connection into the plenti6.3-MIR. (a) 0-300 bp; (b) 300-600 bp; (c) 600-900 bp; 900-1200 bp.

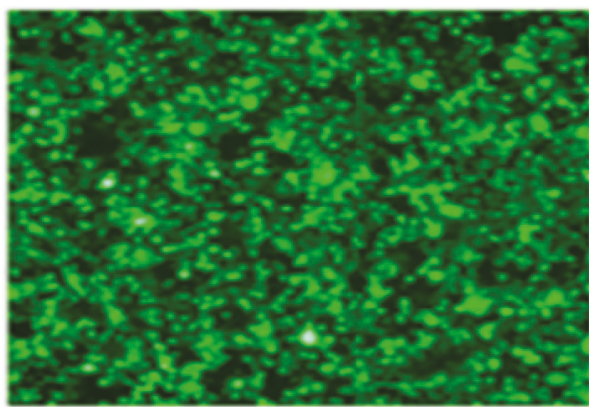

(a)

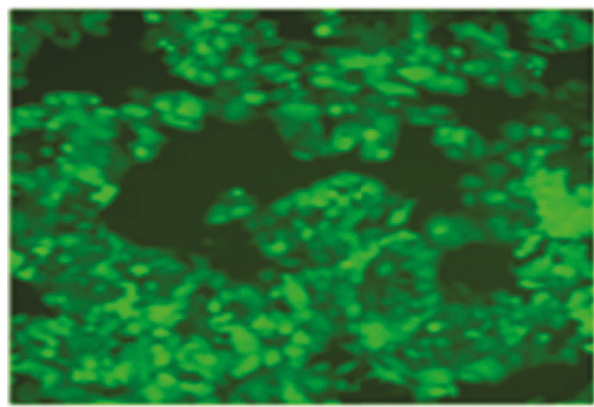

(c)

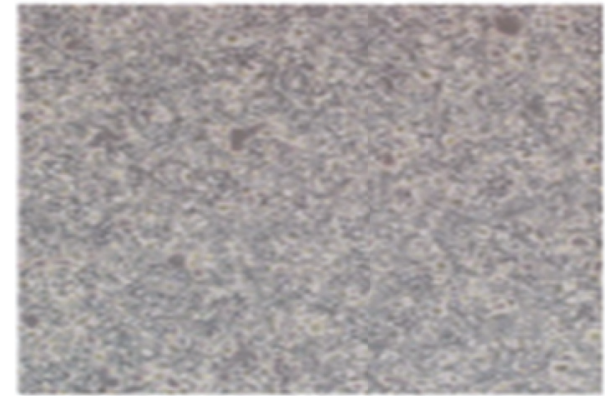

(b)

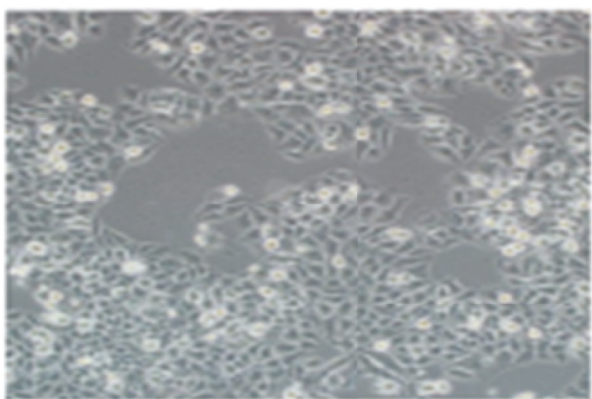

(d)

FIGURE 4: Effect of lentiviral infection after RNAi under the fluorescence microscope ( $\times 100)$. (a) Fluorescence at $24 \mathrm{~h}$ (b) visible light at $24 \mathrm{~h}$. (c) Fluorescence at $48 \mathrm{~h}(\mathrm{~d})$ visible light at $48 \mathrm{~h}$.

TABLE 2: PCR of VEGF expression and interference efficiency.

\begin{tabular}{|c|c|c|c|c|}
\hline Sample & $\triangle \mathrm{CT}$ & $\triangle \triangle \mathrm{CT}$ & $2^{-\triangle \Delta \mathrm{CT}}$ & Interference efficiency \\
\hline MHCC97L-mir200 & 10.652 & 1.847 & 0.278 & 0.722 \\
\hline MHCC97L-NEGA & 8.412 & -0.393 & 1.313 & -0.313 \\
\hline MHCC97L-blank & 8.805 & 0.000 & 1.000 & 0.000 \\
\hline
\end{tabular}




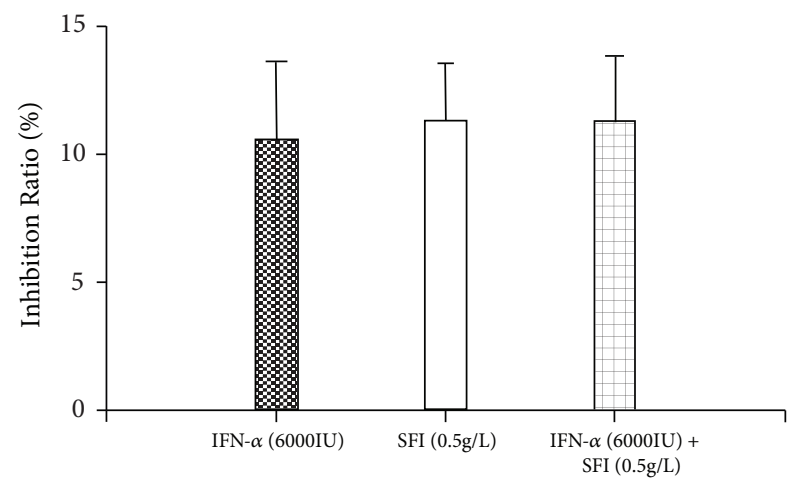

FIGURE 5: Inhibition ratio of SFI and INF- $\alpha$ on MHCC97L-mir200. $\mathrm{P}>0.05$, compared with IFN- $\alpha$ control group, $\mathrm{SD}+$ mean, $\mathrm{n}=5$.

important cytokine for tumor recurrence and development in a variety of solid tumors [25-28], providing a theoretical basis for clinical chemotherapy of carcinomas. SFI is a compound of natural drugs that has already been listed in China, but its mechanism is complex and not completely clear. Therefore, we will try to isolate the effective components in the future study and examine the antitumor effects of the monomer compositions.

\section{Data Availability}

The data used to support the findings of this study are available from the corresponding author upon request.

\section{Conflicts of Interest}

The authors declare that there is no conflict of interests regarding the publication of this paper.

\section{Authors' Contributions}

Xiaoheng Chen, Shuo Qi, and Zhe Li contributed equally to this work.

\section{Acknowledgments}

This research was supported by Key Laboratory of Ministry of Education (Internal Medicine of Traditional Chinese Medicine, Dongzhimen Hospital of Beijing University of Chinese Medicine) and the Nature Science Foundation of China (81673972).

\section{References}

[1] H. Toyoda, T. Kumada, T. Tada et al., "Risk factors of HCC development in non-cirrhotic patients with sustained virologic response for chronic HCV infection," Journal of Gastroenterology \& Hepatology, vol. 30, pp. 1183-1189, 2015.

[2] K. I. Kim, N. Sasase, M. Taniguchi et al., "Prediction of efficacy of interferon treatment of chronic hepatitis $\mathrm{C}$ and occurrence of HCC after interferon treatment by a new classification," Intervirology, vol. 48, no. 1, pp. 52-58, 2005.

[3] M. Flores, C. Chew, K. Tyan, W. Q. Huang, A. Salem, and R. Clynes, "Fc $\gamma$ RIIB prevents inflammatory type I IFN production from plasmacytoid dendritic cells during a viral memory response," The Journal of Immunology, vol. 194, no. 9, pp. 42404250, 2015.

[4] M. G. Brown, S. M. McAlpine, Y. Y. Huang et al., "RNA sensors enable human mast cell anti-viral chemokine production and IFN-mediated protection in response to antibody-enhanced dengue virus infection," PLoS ONE, vol. 7, no. 3, pp. 34-55, 2012.

[5] J. Hou, Z. M. A. Groothuismink, L. Koning et al., "Analysis of the transcriptome and immune function of monocytes during IFN $\alpha$-based therapy in chronic HCV revealed induction of TLR7 responsiveness," Antiviral Research, vol. 109, no. 1, pp.116124, 2014.

[6] L. Cha, E. De Jong, M. A. French, and S. Fernandez, "IFN$\alpha$ exerts opposing effects on activation-induced and IL-7induced proliferation of $\mathrm{T}$ cells that may impair homeostatic maintenance of CD4+T cell numbers in treated HIV infection," The Journal of Immunology, vol. 193, no. 5, pp. 2178-2186, 2014.

[7] W. M. Boedefeld, K. I. Bland, and M. J. Heslin, "Recent insights into angiogenesis, apoptosis, invasion, and metastasis in colorectal carcinoma," Annals of Surgical Oncology, vol. 10, no. 8, pp. 839-851, 2003.

[8] D. Selimovic, H. Ghozlan, O. Abdel-kader, and M. Hassan, "790 hepatitis $\mathrm{C}$ virus core promotes HCC invasion by the induction of vegf-correlated chemokine-1," Journal of Hepatology, vol. 54, no. 11, p. S317, 2011.

[9] T. S. Wang, X. H. Chen, and Z. G. Ding, "Clinical studies in treatment of middle-late stage primary liver cancer," Chinese Journal of Experimental Traditional Medical Formulae, vol. 20, pp. 174-177, 2014.

[10] G. D. Liu and G. Xiao, "Effects of Shengqi Fuzheng injection combined chemotherapy on patients with primary liver cancer," Progress in Modern Biomedicine, vol. 10, no. 07, pp. 1348-1350, 2010.

[11] G. Q. Zhan and R. G. Li, "Effects of ShenqiFuzheng injection on the quality of life in patients with middle and advanced stage primary hepatic carcinoma receiving transcatheter hepatic arterial chemoembolization," J HBUM, vol. 32, no. 4, pp. 325$328,2013$.

[12] A. S. Attele, J. A. Wu, and C.-S. Yuan, "Ginseng pharmacology: multiple constituents and multiple actions," Biochemical Pharmacology, vol. 58, no. 11, pp. 1685-1693, 1999.

[13] T. Yun, "Experimental and epidemiological evidence on nonorgan specific cancer preventive effect of Korean ginseng and identification of active compounds," Mutation Research Fundamental and Molecular Mechanisms of Mutagenesis, vol. 523-524, pp. 63-74, 2003.

[14] M. Lee, S. Sorn, S. Baek, S. Jang, and S. Kim, "Antioxidant and apoptotic effects of Korean white ginseng extracted with the same ratio of protopanaxadiol and protopanaxatriol saponins in human hepatoma HepG2 cells," Annals of the New York Academy of Sciences, vol. 1171, pp. 217-227, 2009.

[15] D. Bensky, A. Gamble, and T. K. Kaptchuk, Chinese Herbal Medicine MateriaMedica, Eastland Press, Seattle, Washington, DC, USA, 1993.

[16] R. K. Zee-Cheng, "Shi-Quan-Da-Bu-Tang (Ten Significant Tonic Decoction), SQT. A potent Chinese biological response modifier in cancer immunotherapy, potentiation and detoxification of anticancer drugs," Methods and Findings in Experimental and Clinical Pharmacology, vol. 14, no. 9, pp. 725-736, 1992.

[17] B. M. Shao, W. Xu, H. Dai, P. Tu, Z. Li, and X. M. Gao, "A study on the immune receptors for polysaccharides from the 
roots of Astragalus membranaceus, a Chinese medicinal herb," Biochemical and Biophysical Research Communications, vol. 320, no. 4, pp. 1103-1111, 2004.

[18] P. Duan and Z. M. Wang, "Clinical study on effect of Astragalus in efficacy enhancing and toxicity reducing of chemotherapy in patients of malignant tumor," Zhongguo Zhong Xi Yi Jie He Za Zhi Zhongguo Zhongxiyi Jiehe Zazhi, vol. 22, no. 7, pp. 515-517, 2002.

[19] ZG. Ding, NQ. Li, and DS. Tao, "Effects of ShenqiFuzheng injection on gene expression profile of liver tissue with metastatic carcinoma in mice," Chinese Journal of Integrated Traditional \& Western Medicine, vol. 28, no. 2, pp. 135-138, 2008.

[20] M. G. Tutton, M. L. George, S. A. Eccles, S. Burton, R. I. Swift, and A. M. Abulafi, "Use of plasma MMP-2 and MMP-9 levels as a surrogate for tumour expression in colorectal cancer patients," International Journal of Cancer, vol. 107, no. 4, pp. 541-550, 2003.

[21] K. K. W. Auyeung, P. C. Law, and J. K. S. Ko, "Novel antiangiogenic effects of formononetin in human colon cancer cells and tumor xenograft," Oncology Reports, vol. 28, no. 6, pp. 21882194, 2012.

[22] Y. Qiao, P. J. Zhang, X. T. Lu et al., "Panax notoginseng saponins inhibits atherosclerotic plaque angiogenesis by downregulating vascular endothelial growth factor and nicotinamide adenine dinucleotide phosphate oxidase subunit 4 expression," Chinese Journal of Integrative Medicine, vol. 21, no. 4, pp. 259265, 2015.

[23] J. Du, B. C. Y. Cheng, X. Q. Fu et al., "In vitro assays suggest Shenqi Fuzheng Injection has the potential to alter melanoma immune microenvironment," Journal of Ethnopharmacology, vol. 194, pp. 15-19, 2016.

[24] Y. Yang, W. Ting, L. Xiao et al., "Immunoregulation of shenqi fuzheng injection combined with chemotherapy in cancer patients: a systematic review and meta-analysis," EvidenceBased Complementary and Alternative Medicine, vol. 2017, Article ID 5121538, 16 pages, 2017.

[25] R. Raman and D. Vaena, "Immunotherapy in metastatic renal cell carcinoma: a comprehensive review," BioMed Research International, vol. 2015, Article ID 367354, 8 pages, 2015.

[26] M. Xie, L. Zhou, X. Chen et al., "Progesterone and src family inhibitor PP1 synergistically inhibit cell migration and invasion of human basal phenotype breast cancer cells," BioMed Research International, vol. 2015, Article ID 426429, 14 pages, 2015.

[27] N. Hamilton, D. Márquez-Garbán, V. Mah et al., "Biologic roles of estrogen receptor- $\beta$ and insulin-like growth factor- 2 in triple-negative breast cancer," BioMed Research International, vol. 2015, Article ID 925703, 15 pages, 2015.

[28] J. Reszec, A. Hermanowicz, R. Rutkowski, G. Turek, Z. Mariak, and . Chyczewski, "Expression of MMP-9 and VEGF in meningiomas and their correlation with peritumoral brain edema," BioMed Research International, vol. 2015, Article ID 646853, 8 pages, 2015. 


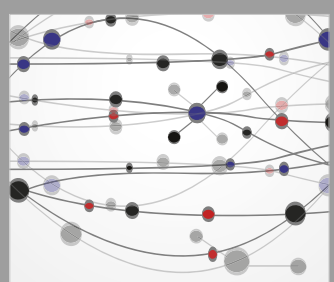

The Scientific World Journal
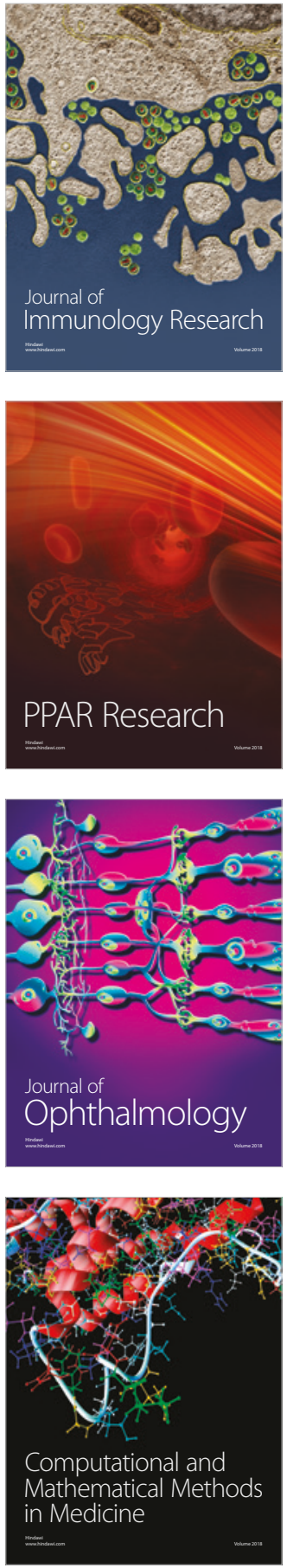

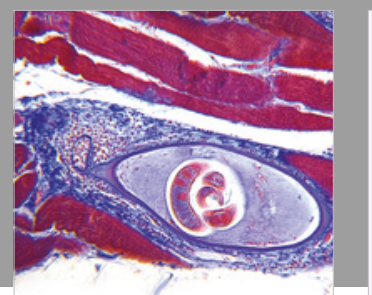

Gastroenterology Research and Practice

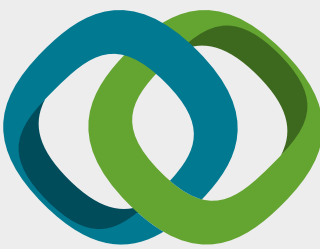

\section{Hindawi}

Submit your manuscripts at

www.hindawi.com
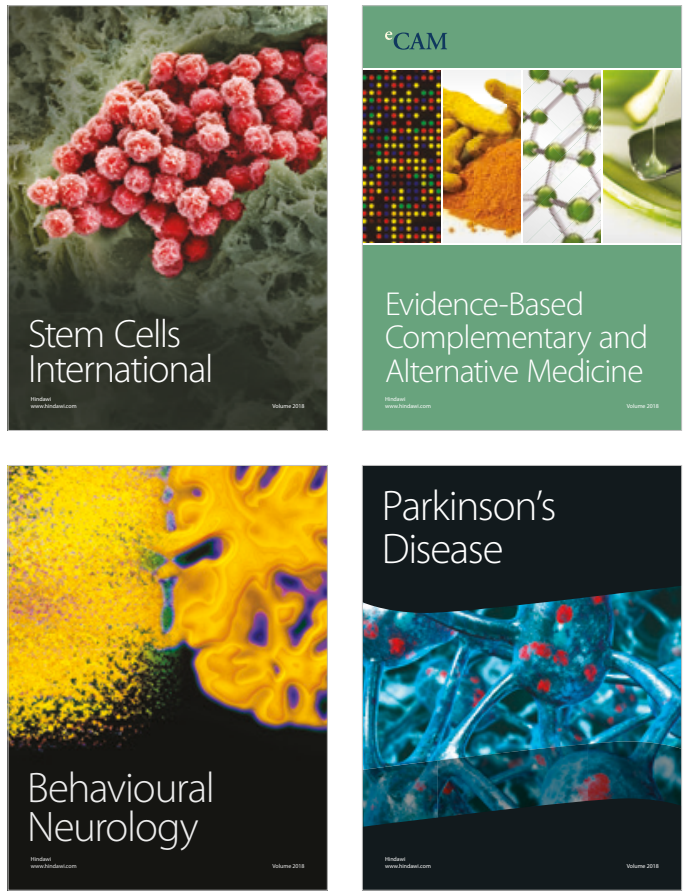

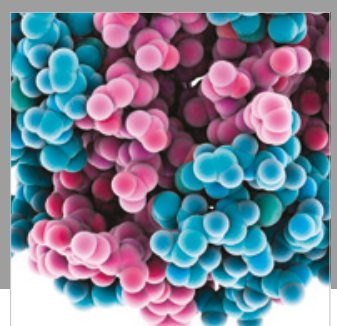

ournal of

Diabetes Research

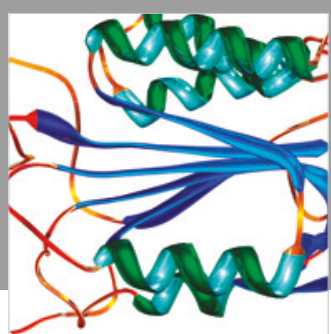

Disease Markers
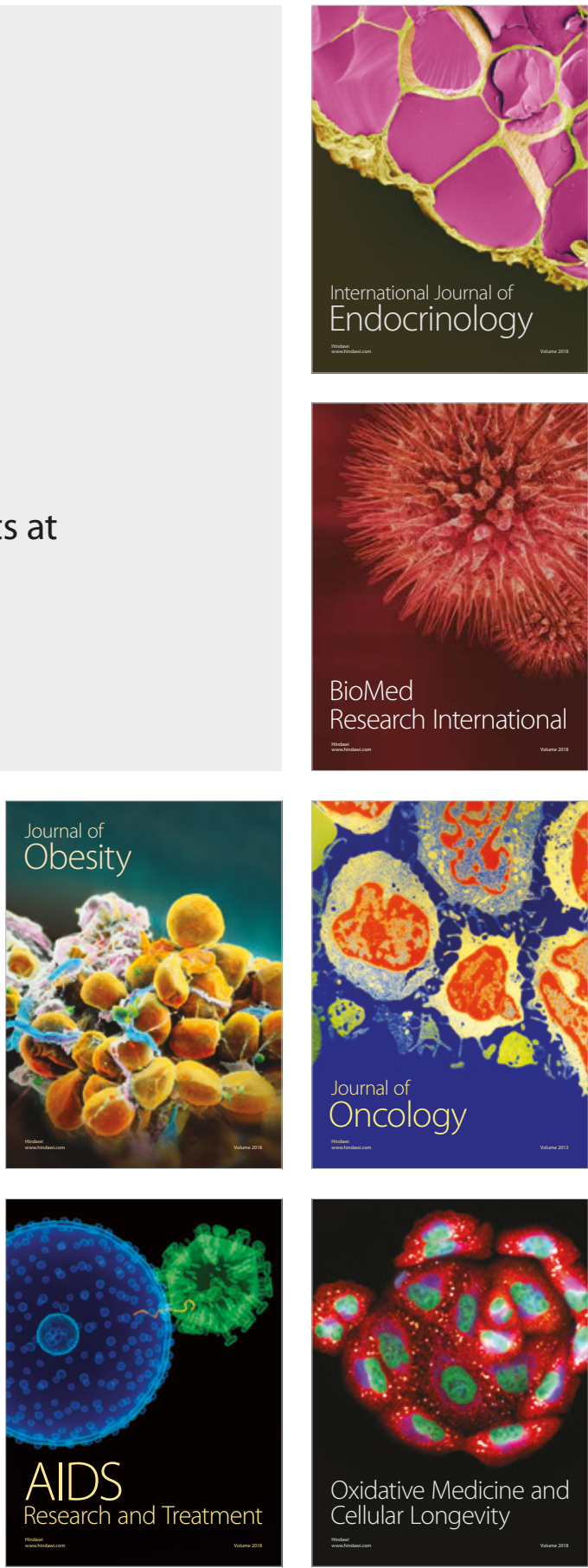